\title{
Novel Cathelicidin Antimicrobial Peptides from Paa robertingeri
}

\author{
Qinghua Luo ${ }^{1 \#}$, Huaiqing Deng ${ }^{1 \#}$, Mengguang Yin ${ }^{1}$, Chen Chen ${ }^{1}$ \\ and Jiang Zhou ${ }^{1^{*}}$ \\ ${ }^{1}$ School of Life Sciences, Guizhou Normal University, Guiyang, Guizhou, 550001, China.
}

Authors' contributions

This work was carried out in collaboration among all authors. Author JZ designed the study, performed the statistical analysis and wrote the protocol. Author CC wrote the first draft of the manuscript. Authors HD and MY managed the analyses of the study. Author QL managed the literature searches. All authors read and approved the final manuscript.

Article Information

DOI: 10.9734/ARRB/2019/v32i430093 Editor(s):

(1) Dr. David E. Martin, Martin Pharma Consulting, LLC, Shawnee, OK, USA.
Reviewers:

(1) Mohini Chetan Kuchekar, Pune University, India. (2) Oshim, Ifeanyi Onyema, Nnamdi Azikiwe University, Nigeria. Complete Peer review History: http://www.sdiarticle3.com/review-history/50001

Original Research Article

Received 02 May 2019

Accepted 10 July 2019

Published 02 August 2019

\begin{abstract}
This study aimed to describe two cathelicidins (cathelicidin-PR1 and cathelicidin-PR2) from the skin of Paa robertingeri (Anura: Ranidae). The deduced mature peptides cathelicidin-PR1 and cathelicidin-PR2 were composed of 29 and 25 residues, respectively. Cathelicidin - PR1 has higher antimicrobial activity it could kill Gram-positive and Gram-negative bacteria and even some fungal species. Cathelicidin-PR1 exhibited more effective than AMP in antimicrobial activity against Pseydomonas maltophilia clinical strain. On the contrary, cathelicidin-PR2 had very weak antimicrobial activity. Furthermore, cathelicidin-PR1 and cathelicidin-PR2 exhibited very low hemolytic activity against human erythrocytes and little hemagglutinating activity. The results suggested that the cathelicidin-PR1 might serve as a template for developing novel antibiotics.
\end{abstract}

Keywords: Antimicrobial activity; antimicrobial peptide; hemagglutinating activity; hemolytic activity; Paa robertingeri.

*Corresponding author: E-mail: zhoujiang@ioz.ac.cn, 201402005@gznu.edu.cn;

"These authors contributed to the work equally and are regarded as co-first authors. 


\section{INTRODUCTION}

Antimicrobial peptide (AMP) is a kind of smallmolecule peptides characterized by strong and broad-spectrum bactericidal activity. In the last 30 years, the widespread distribution of AMPs has been discovered, providing insights into the innate defensive systems that permit multicellular organisms to live in harmony with microbes [1]. Cathelicidins and defensins are the two major AMP families in mammals [2,3]. They can defence against a variety of harmful microorganisms. The presence of cathelicidins in hagfish, the oldest jawless craniates, indicates that cathelicidin genes appeared early in phylogenesis [4-6], which illustrates their important role. Almost 100 kinds of cathelicidins were searched from the Antimicrobial Peptide Database (http://aps.unmc.edu/AP/main.php), and the data are constantly updated.

Since the discovery of the first cathelicidin (Bac5) from the cDNA of the bovine neutrophils [7], a variety of new cathelicidins have been found in most of the vertebrates, ranging from mammalians, birds, reptiles, amphibians to fishes $[8,9]$. Cathelicidins possess a conserved structure. Upon activation, most of the cathelicidin precursors are proteolytically cleaved to release the $\mathrm{C}$-terminal mature peptide domain $[5,6,10,11]$. On the basis of the protein secondary structure, cathelicidins can be divided into four categories: $\alpha$-helix cathelicidins, extension-spiral cathelicidins, cyclic cathelicidins, and $\beta$-sheet cathelicidins. Cathelicidins derived from mammals are mostly $\alpha$-helical, and the primary structure generally contains 23-40 amino acids $[12,13]$. Most of the cathelicidins antibacterial peptides are the $\alpha$-helical structure [14]. $\beta$-sheet cathelicidins generally contain 16-18 amino acids, which are folded into a hairpin structure stabilized by disulfide bonds [15].

A known mechanism of action of amphibian antimicrobial peptides is that the positively charged polypeptides interact with the microbial cell membrane and induce changes in the membrane structure, resulting in the cytoplasm outflow and eventually causing microbial death [16]. However, evidence shows that the cell membrane is not the only target of antimicrobial peptides. They also act on other parts of microorganisms, such as intracellular DNA and RNA, thereby interfering with microbial metabolic pathways [17].

The amphibians face the challenge of adapting to moist environments. Their skins secrete a large volume and variety of antimicrobial peptides. Also, amphibians lack lymphocytes. Hence, the secretion of mucous substances is particularly important in such an environment [18]. In this study, two cathelicidins were identified and characterized by Paa robertingeri.

\section{MATERIALS AND METHODS}

\subsection{Tissue Preparation}

An adult specimen of Paa robertingeri was captured from Fanjingshan in Guizhou province $\left(108^{\circ} 45^{\prime} 55^{\prime \prime}-108^{\circ} 48^{\prime} 30^{\prime \prime}\right.$ E; $27^{\circ} 49^{\prime} 50^{\prime \prime}-28^{\circ} 1^{\prime} 30^{\prime \prime}$ N). A $1-\mathrm{cm}^{2}$ piece of dorsal skin was removed from its back immediately and stored in liquid RNA protector (sample protector for RNA/DNA, TaKaRa, Japan) until use. After collection, this frog was sterilized with alcohol and then set free in its natural habitat.

\section{2 cDNA Library Construction and Screening of the Skin cDNAs Encoding Cathelicidins}

The stored skin was washed in water and then ground into powder in liquid nitrogen. The total RNA was extracted using TriZol reagent (Life Technologies, CA, USA). Then, the total RNA was used to construct the cDNA library using the Creator Smart cDNA Library Construction Kit (Clontech, CA, USA). First-strand cDNA synthesis was performed using SMARTScribe Reverse Transcriptase (Clontech) and SMARTer V Oligonucleotide and 3' IF SMARTer CDS Primer. Second-strand cDNA synthesis was performed by a long-distance polymerase chain reaction (PCR) method using Advantage 2 Polymerase Mix (Clontech) in the presence of $5^{\prime}$ PCR Primer II A and 3' IF SMARTer PCR Primer. The synthesized cDNA was used as a template for the following PCR to screen the cDNAs encoding the cathelicidin peptides [18].

On the basis of the conserved signal peptide domain of previously characterized host defence peptide (HDP) from ranid frogs, a sense oligonucleotide primer (5'CCCCATGTTCACCTTGAAG-3') was designed and coupled with $3^{\prime}$ antisense primer (5'TACGCGACGCGATACGCGAAT-3') according to the sequence of $3^{\prime}$ IF SMARTer CDS primer to screen the HDP encoded cDNAs. The PCR procedure was as follows: $5 \mathrm{~min}$ of denaturation at $94^{\circ} \mathrm{C} ; 30$ cycles: denaturation at $94^{\circ} \mathrm{C}$ for $30 \mathrm{~s}$, primer annealing at ${ }^{\circ} \mathrm{C}$ for $30 \mathrm{~s}$, and extension at 
$72^{\circ} \mathrm{C}$ for $1 \mathrm{~min}$. The PCR product was purified by gel electrophoresis and cloned into pMD19-T vector (TaKaRa, Japan) for sequencing.

\subsection{Alignment of Amphibian Cathelicidins}

Sequencing results used the National Center for Biotechnology Information (NCBI) Basic Local Alignment Search Tool to remove the carrier and identify the fragment. Then the fragment sequences were translated into amino acids by ExPASy (http://www.expasy.org/). The sequences were input into NCBI database, the complete gene sequence encoding cathelicidins of $P$. robertingeri was identified, and the amino acid sequence of the mature peptide was predicted according to the characterized cathelicidins.

\subsection{Peptide Synthesis}

Cathelicidin-PR1 and -PR2 were synthesized by GL Biochem Ltd. (Shanghai, China) and analyzed by high-performance liquid chromatography and mass spectrometry to ensure purity of more than $95 \%$.

\subsection{Antimicrobial Assay}

Seven strains of standard and clinically isolated microorganisms, including Gram-positive bacteria, Gram-negative bacteria, and fungi, were used in the antimicrobial assay. Minimal inhibitory concentrations (MICs) of the peptides were determined by a standard twofold microdilution method in a 96-well microtiter plate, as described previously [19]. Briefly, the microorganisms were incubated in Mueller-Hinton broth (MH) at $37^{\circ} \mathrm{C}$ to exponential phase and diluted with fresh $\mathrm{MH}$ broth to $10^{6}$ colony-forming unit (CFU)/mL. Then, $50 \mu \mathrm{L}$ of serial dilutions of peptides in $\mathrm{MH}$ broth were prepared in 96-well microtiter plates and mixed with $50 \mu \mathrm{L}$ of diluted bacterial inoculum. The plates were incubated at $37^{\circ} \mathrm{C}$ for $18 \mathrm{~h}$, and the minimal concentration at which no visible growth occurred was recorded. The traditional antibiotic ampicillin was used as a positive control, and the assay was conducted in triplicate.

\subsection{Bacterial Killing Kinetics Assay}

The bacterial killing kinetics of cathelicidin-PR1 against Bacillus cereus clinical strain was determined by measuring the changes in the viable bacterial counts after peptide treatment. $B$. cereus clinical strain was incubated in the Luria-
Bertani (LB) liquid medium at $35^{\circ} \mathrm{C}$ and $200 \mathrm{rpm}$ for $10-16 \mathrm{~h}$ and diluted to $10^{5} \mathrm{CFU} / \mathrm{mL}$ in the fresh LB liquid medium. Cathelicidin-PR1 was added to the bacterial suspension to a final concentration of $5 \times \mathrm{MIC}$, and the bacterial suspension was incubated at $37^{\circ} \mathrm{C}$ for $0,10,20$, $30,45,60,90$, and $120 \mathrm{~min}$. At each time point, aliquots $(10 \mu \mathrm{L})$ were removed and diluted with fresh LB broth 100 times. Next, $100 \mu \mathrm{L}$ of the dilutions were coated on the LB solid medium and incubated for $10-16 \mathrm{~h}$ at $37^{\circ} \mathrm{C}$. The viable colonies were counted. Ampicillin was used as a positive control, and sterile deionized water was used as a negative control, the assay was conducted in triplicate at least and took the average.

\subsection{Hemolytic Assay}

Fresh human erythrocytes were collected, mixed in $5 \mathrm{~mL}$ of mixing Alsever's solution $(8.0 \mathrm{~g}$ sodium citrate, $0.55 \mathrm{~g}$ citric acid, $20.5 \mathrm{~g}$ glucose, and $4.2 \mathrm{~g} \mathrm{NaCl}$ in $1 \mathrm{~L}$ deionized $\mathrm{H}_{2} \mathrm{O}, \mathrm{pH}$ 6.1) at a volume ratio of $1: 1$, and centrifuged at 1000 $\mathrm{rpm}$ for $5 \mathrm{~min}$. The supernatant was removed, washed with $0.9 \%$ saline three or four times, and resuspended to a final concentration of $2 \%(\mathrm{v} / \mathrm{v})$. Serial dilutions of cathelicidin-PR1 and cathelicidin-PR2 were incubated with the erythrocyte solutions at $37^{\circ} \mathrm{C}$ for $30 \mathrm{~min}$, and then the cells were centrifuged at $1500 \mathrm{rpm}$ for $10 \mathrm{~min}$. The supernatant was collected, and the absorbance at $540 \mathrm{~nm}$ was measured. The assay was conducted in triplicate. $1 \%$ Triton $\mathrm{X}$ $100(\mathrm{v} / \mathrm{v})$ was used as a positive control, and $0.9 \%$ saline was used as a negative control. The assay was conducted in triplicate at least. Percentage of hemolysis $(1 \%)$ was calculated according to the following formula:

$I \%=\left(A_{\text {sample }}-A_{\text {negative control }}\right) /\left(A_{\text {positive control }}-A_{\text {negative }}\right.$ control) $\times 100 \%$

\subsection{Anti-oxidant Assay}

2,2-Diphenyl-1-picrylhydrazyl (DPPH) is a stable aliphatic nitrogen-centered radical. It can be used to detect the anti-oxidant activity of antimicrobial peptides by radical scavenging assay. DPPH (Sigma, USA) was dissolved in methanol to a final concentration of $6 \times 10^{-5} \mathrm{M}$. Next, $192 \mu \mathrm{L}$ of DPPH solutions were mixed with $8 \mu \mathrm{L}$ of serial concentrations of peptide solutions. The mixture was incubated in the dark at room temperature for $30 \mathrm{~min}$, and the amount of reduced DPPH was quantified by measuring a decrease in absorbance at $517 \mathrm{~nm}$. Deionized water was used as a negative control. 
Inhibition of free radicals by DPPH in percentage $(I \%)$ was calculated according to the formula:

$$
I \%=\left(A_{\text {blank }}-A_{\text {sample }}\right) / A_{\text {blank }} \times 100 \%
$$

\subsection{Erythrocyte Hemagglutination Assay}

Lectins are glycan-binding proteins that can specifically recognize glycan structures and have been identified from a wide variety of organisms [20]. Fresh human erythrocytes were collected and stored in Alsever's solution to prevent coagulation. The assay was performed in U-well microtiter plates (96 wells) according to the method described by $\mathrm{Li}$ et al. [21]. The erythrocytes were washed twice with Tris buffered saline (TBS) buffer $(6.06 \mathrm{~g}$ Tris base and $5.84 \mathrm{~g} \mathrm{NaCl}$ in $1 \mathrm{~L}$ of $\mathrm{H}_{2} \mathrm{O}, \mathrm{pH} 7.5$ ) and TBS $+\mathrm{Ca}^{2+}$ buffer (6.06 $\mathrm{g}$ Tris base, $5.84 \mathrm{~g} \mathrm{NaCl}$, and $1.12 \mathrm{~g} \mathrm{CaCl}_{2}$ in $1 \mathrm{~L}$ of $\left.\mathrm{H}_{2} \mathrm{O}, \mathrm{pH} 7.5\right)$, centrifuged at $1000 \mathrm{rpm}$ for $5 \mathrm{~min}$, and resuspended in the same buffer to a final concentration of $2 \%(\mathrm{v} / \mathrm{v})$. Then, $10 \mu \mathrm{L}$ of peptide solutions $(2 \mathrm{mg} / \mathrm{mL})$ were mixed with $90 \mu \mathrm{L}$ of erythrocyte solutions in a Uwell microtiter plate. The plate was incubated at room temperature for $45 \mathrm{~min}$, and the result was observed. Deionized water was used as negative control, and the assay was conducted in triplicate.

\subsection{Bioinformatics Analysis Structure Prediction}

The physical and chemical parameters of cathelicidin-PR1 and cathelicidin-PR2 were determined by the Prot Param tool (http://web.expasy.org/protparam/) through ExPASy Bioinformatics Resource. The secondary structure was predicted using the PSIPRED protein structure prediction server provided by Bioinformatics Group of UCL Department of Computer Science (http://bioinf.cs.ucl.ac.uk/psipred/).

\subsection{Circular Dichroism Analysis/ Spectroscopy}

The samples were prepared by dissolving the peptide powder in $60 \mathrm{mM}$ sodium dodecyl sulfate (SDS) $/ \mathrm{H}_{2} \mathrm{O}$ solutions to a concentration of 0.5 $\mathrm{mg} / \mathrm{mL}$. The spectra were measured at $298 \mathrm{~K}$ $\left(25^{\circ} \mathrm{C}\right)$ between 192 and $250 \mathrm{~nm}$ using a $0.1-\mathrm{cm}$ path length cell with 1-nm bandwidth, 1-s response time, and a scan speed of $100 \mathrm{~nm} / \mathrm{min}$. Three consecutive scans per sample were performed and averaged, followed by subtraction of the solvent signal.

\section{RESULTS AND DISCUSSION}

\subsection{Identification and Characterization of $P$. robertingeri Cathelicidins}

Total RNA was extracted from the skin of $P$. robertingeri, and cDNA library was constructed using a cDNA library construction kit. Two cDNAs encoding two different cathelicidins were obtained from the cDNA library by the PCRbased cDNA cloning method. The complete nucleotide sequences and translated amino acid sequences of the two cathelicidin precursors are shown in Fig. 1. The cDNAs encoding cathelicidin-PR1 and cathelicidin-PR2 precursors were composed of $587 \mathrm{bp}$ and $607 \mathrm{bp}$, respectively. The translated protein precursors comprised of 147 and 145 amino acid residues, respectively. Consistent with other cathelicidins, precursors of cathelicidin-PR1 and cathelicidinPR2 possessed a typical signal peptide sequence, a highly conserved cathelin domain, and a cationic C-terminal mature peptide sequence.

The mature peptides of cathelicidin-PRs were predicted in this study. Cathelicidin-PR1 was composed of 29 amino acid residues, and the amino acid sequence was RKCNLFCKAKQKLKSLSSVIGTVVHPPRG. In contrast, cathelicidin-PR2 was composed of 25 amino acid residues, and the amino acid sequence was KECKDYLCKLLMKLG SSSHIESIDP.

\subsection{Antimicrobial Activity of cathelicidin- PRs}

Cathelicidin-PR1 and cassthelicidin-PR2 were chemically synthesized and their purity was confirmed to be $95 \%$. The minimal inhibitory concentrations (MICs) of the two peptides against seven microorganisms, including Grampositive bacteria, Gram-negative bacteria, and fungi, were determined. As listed in Table 1, except for Acinetobacter baumannii, cathelicidinPR1 exhibited potent and broad-spectrum antimicrobial activity against most in the tested clinical strain. Cathelicidin-PR1 is more effective than AMP in antimicrobial activity against Pseydomonas maltophilia clinical strain. Unlike cathelicidin-PR1, cathelicidin-PR2 exhibited very weak antimicrobial activity.

\subsection{Bacterial Killing Kinetics of cathelicidin-PR1}

Using ampicillin as a positive control, the killing kinetics of cathelicidin - PR1 against 
Table 1. Antimicrobial activity of cathelicidin-PR1 and cathelicidin-PR2

\begin{tabular}{llll}
\hline Microorganisms & \multicolumn{3}{c}{ Minimal inhibitory concentrations $(\boldsymbol{\mu g} / \mathbf{m l})$} \\
\cline { 2 - 4 } & Cathelicidin-PR1 & Cathelicidin-PR2 & Amp \\
\hline Acinetobacter baumannii clinical strain & $>100$ & $>100$ & 4.69 \\
Pseydomonas maltophilia clinical strain & 75 & $>100$ & $>100$ \\
Staphylococcus aureus clinical strain & 37.5 & $>100$ & $<0.10$ \\
Bacillus cereus clinical strain & 37.5 & $>100$ & 4.69 \\
Bacillus subtilis clinical strain & 37.5 & $>100$ & 4.69 \\
Candida albicans clinical strain & 37.5 & $>100$ & 4.69 \\
Candida glabrata clinical strain & 37.5 & $>100$ & 4.69 \\
\hline
\end{tabular}

\begin{tabular}{|c|c|}
\hline in-PRl & \\
\hline gtgtgctatggatctccgctctcacgttgcaggcggctcgctctcagtctccggatcaggaa 62 & \\
\hline 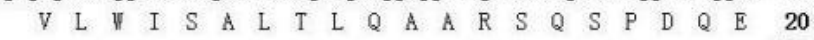 & \\
\hline atgggtcagagaggccttggatctctacaaccagagggaagatggagagttcttcttt & \\
\hline 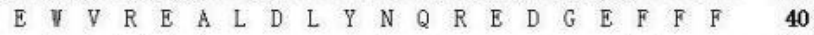 & \\
\hline aagttcctgtctgatctcccggacgccctcctggaggaggaggagggagactctccagcc & \\
\hline 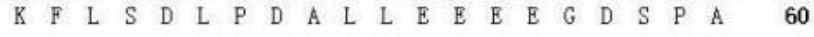 & \\
\hline atcggcttcctaatcaaggagacggaatgccccaaatccgaagactgcgacttggagaaa & \\
\hline 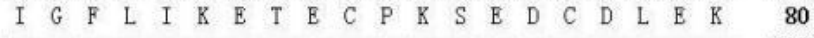 & \\
\hline tgcgactacaggaaggacggggaggtgaaggtctgcgctctgtaccgggaggaagaggac & \\
\hline 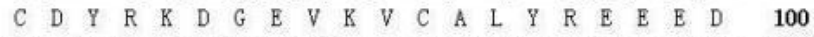 & \\
\hline gtgaagtgcgtcagtctgtccgagaat tcacgcgcccggcgggccagcaacaagcggaag & \\
\hline 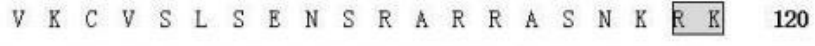 & \\
\hline tgtaacttgttctgcaaagcgaagcagaagctgaaatctctgagctccgtcatcgggacg & \\
\hline $\begin{array}{cccccccccccccccccccc}E & N & L & F & C & \mathbb{K} & A & K & Q & K & L & \mathbb{K} & S & L & S & S & V & I & G & T \\
\end{array}$ & \\
\hline gtcgttcatccacctcgaggatgaacggcatttcgctgctgcggcggcgcaaaagaacg & \\
\hline \begin{tabular}{|lllllllllll}
$V$ & $V$ & $H$ & $P$ & $P$ & $R$ & $G$ & - \\
\end{tabular} & \\
\hline cggcggcagcgccgaccgccaacgcttctcgcaccgggcaaactatcactgcgcttccaa & \\
\hline atccagaataatcaataaaaccttcataaatccttcgtatatgat & \\
\hline cathelicidin-PR2 & \\
\hline gtgtgctatggatctccgctctcacattgcaggcggctcgctctcagtctccggatcaggaa & 62 \\
\hline 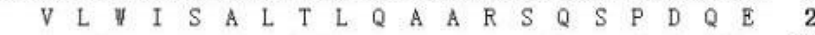 & 20 \\
\hline gaatgggtcagagaggcct tggatctctacaaccagagggaagatggagagtgcttcttt & 122 \\
\hline 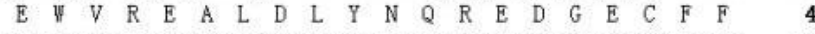 & 40 \\
\hline aaat tcctgtctgatctcccggacgccctcctggaggaggaaaacgatccgacaatcacg & 182 \\
\hline 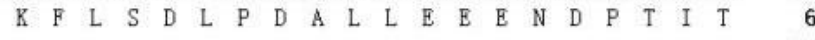 & 60 \\
\hline ttcttaataaaggagacggaatgcctgaaatctgaagatatcaact tggaggaatgtgac & 242 \\
\hline 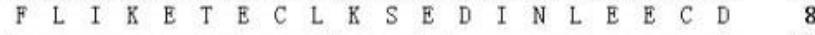 & 80 \\
\hline tacaagaaggacggggaggtgaaggtctgcggatggtacccggaggagggggagaccatg & 302 \\
\hline 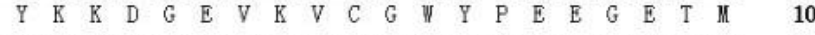 & 100 \\
\hline aagactctgaaatgtgtcagcctgaccaagaattttcgcgccaagcgagccaccagtaaa & 362 \\
\hline 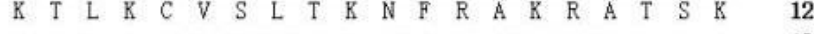 & 120 \\
\hline aaagagtgcaaagattatttgtgtaaactgcttatgaaacttggatcctccagccacatc & 422 \\
\hline 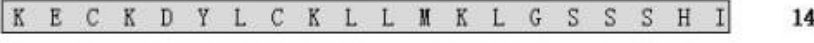 & 140 \\
\hline gaaagcatcgatccctgaccatcgcaaggcgctcagcagtaacgcacgcttggaggggca & 482 \\
\hline \begin{tabular}{|llllll}
$E$ & $S$ & $I$ & $D$ & $P$ & - \\
\end{tabular} & 145 \\
\hline aact ttct tgtacctcotttgtcagatacgacgettatgttcogcta & 542 \\
\hline tcagctgaaagttctgtacattgtatcacatgacgcaaa tacaat taaagct ttgggct & 602 \\
\hline & 607 \\
\hline
\end{tabular}

Fig. 1. cDNA sequences encoding cathelicidin-PR1 and the predicted prepropeptide sequences. The putative mature peptides of cathelicidin-PRs are boxed and shaded

Bacillus cereus clinical strain was investigated by a colony counting method. As illustrated in Table 2 , at a concentration of $5 \times \mathrm{MIC}$, cathelicidin-PR1 rapidly exerted its antimicrobial function. It just took $45 \mathrm{~min}$ for cathelicidin-PR1 to kill all the $B$. cereus clinical strain cells. More importantly, the 
colony forming units (CFUs) remained zero when the incubation time was extended to $120 \mathrm{~min}$, implying that the antimicrobial property of cathelicidin-PR1 was lethal. In contrast, at the same concentration of $5 \times \mathrm{MIC}$, it took at least $90 \mathrm{~min}$ for the positive control ampicillin to completely kill the $B$. cereus clinical strain cells.

It indicated that cathelicidin-PR1 could rapidly and efficiently kill $B$. cereus clinical strain cells. Therefore, cathelicidin-PR1 might be used as a potential antibiotic.

\subsection{Hemolytic and Anti-oxidant Activity}

Cathelicidin-PR1 did not show any hemolytic activity. At a concentration of $200 \mu \mathrm{g} / \mathrm{mL}$, the rate of hemolysis of cathelicidin-PR1 and cathelicidinPR2 was $1.78 \%$ and $2.01 \%$, respectively. However, at a concentration of $100 \mu \mathrm{g} / \mathrm{mL}$, the rate of hemolysis of cathelicidin PRs was $3.87 \%$ and $1.12 \%$, respectively (Table 3).

At a concentration of $80 \mu \mathrm{g} / \mathrm{mL}$, cathelicidin-PR1 and cathelicidin-PR2 showed slight DPPH radical scavenging activity, with $1 \%$ values of $2.92 \%$ and $2.30 \%$, respectively.

\subsection{Erythrocyte Hemagglutinating Activity}

In this study, cathelicidin-PR1 did not show any hemagglutinating activity irrespective of the presence of $\mathrm{Ca}^{2+}$. However, cathelicidin-PR2 showed a weak hemagglutinating activity in the presence of $\mathrm{Ca}^{2+}$, but it did not show any hemagglutinating activity in the absence of $\mathrm{Ca}^{2+}$ (Fig. 2).

\subsection{Physical Properties Analysis and Secondary Structure Prediction}

The physical and chemical parameters of the two cathelicidin-PRs were computed by ProtParam (http://web.expasy.org/protparam/); they are listed in Table 4. Besides, the secondary structures of the two cathelicidin-PRs were also predicted by the online prediction software from the University College London (UCL) Department of Computer Science (http://bioinf.cs.ucl.ac.uk/psipred/). CathelicidinPR1 was mainly composed of a helix and random coil (Fig. 3). Cathelicidin-PR2 was similar to cathelicidin-PR1.

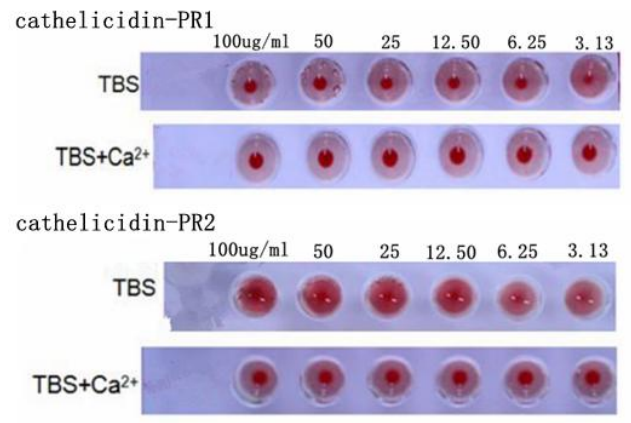

Fig. 2. Erythrocyte hemagglutinating activity of different concentrations of cathelicidin-PRs

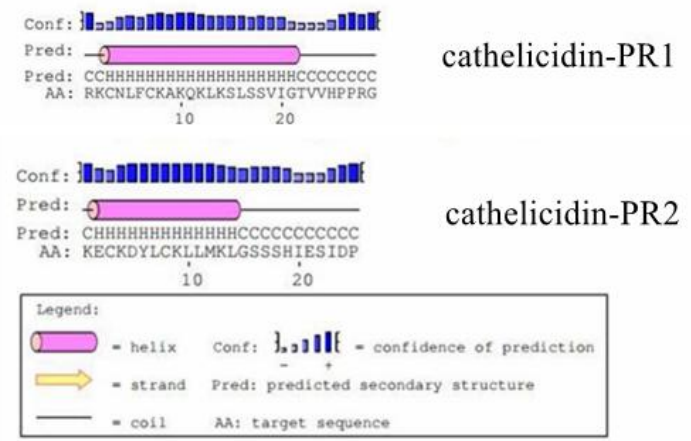

Fig. 3. Secondary structure prediction of cathelicidin-PRs 
Table 2. Bacterial killing kinetics of cathelicidin PR1 against Bacillus cereus clinical strain

\begin{tabular}{|c|c|c|c|c|c|c|c|c|}
\hline \multirow[t]{2}{*}{ Time } & \multicolumn{8}{|c|}{ Colony Forming Units (CFUs) } \\
\hline & Omin & 10min & $20 \mathrm{~min}$ & $30 \mathrm{~min}$ & $45 \mathrm{~min}$ & $1 \mathrm{~h}$ & $1.5 \mathrm{~h}$ & $2 \mathrm{~h}$ \\
\hline cathelicidin-PR1(5xMIC) & $49.33 \pm 12.06$ & $51 \pm 8.19$ & $41 \pm 3.00$ & $14.33 \pm 7.02$ & $0 \pm 0.00$ & $0 \pm 0.00$ & $0 \pm 0.00$ & $0 \pm 0.00$ \\
\hline Ampicillin(5xMIC) & $37.67 \pm 6.11$ & $31.33 \pm 11.15$ & $26.67 \pm 11.02$ & $15.67 \pm 2.52$ & $7.00 \pm 2.65$ & $1.33 \pm 2.31$ & $0.33 \pm 0.58$ & $0 \pm 0.00$ \\
\hline Blank control (sterile water) & $39.67 \pm 10.07$ & $32.33 \pm 7.57$ & $26.33 \pm 3.06$ & $55 \pm 9.64$ & $95.67 \pm 20.21$ & $98.33 \pm 14.57$ & $132.33 \pm 15.37$ & $219.67 \pm 11.15$ \\
\hline
\end{tabular}

Note: $5 \times M I C$ is 5 times of the minimum inhibitory concentration; cathelicidin-PR1 concentration is $187.5 \mathrm{ug} / \mathrm{ml}$; ampicillin concentration is $23.45 \mathrm{ug} / \mathrm{ml}$; the results are the average value of three independent repeated experiments $(M \pm S D)$ 
Table 3. Physical and chemical parameters of cathelicind-PR1 and cathelicind-PR2

\begin{tabular}{llllll}
\hline Peptide & $\begin{array}{l}\text { Number } \\
\text { of amino } \\
\text { acids }\end{array}$ & $\begin{array}{l}\text { Molecular } \\
\text { weight (Da) }\end{array}$ & $\begin{array}{l}\text { Net } \\
\text { charge }\end{array}$ & $\begin{array}{l}\text { Theoretical } \\
\text { pl }\end{array}$ & $\begin{array}{l}\text { Grand Average of } \\
\text { Hydropathicity } \\
\text { (GRAVY) }\end{array}$ \\
\hline Cathelicidin-PR1 & 29 & 3195.88 & +7 & 10.59 & -0.226 \\
Cathelicidin-PR2 & 25 & 2838.34 & 0 & 6.74 & -0.328 \\
\hline
\end{tabular}

Table 4. The hemolysis ratios of cathelicidin-PR1 and cathelicidin-PR2

\begin{tabular}{lll}
\hline & cathelicidin-PR1 & cathelicidin-PR2 \\
\hline $100 \mathrm{ug} / \mathrm{ml}$ & $3.87 \%$ & $1.12 \%$ \\
$200 \mathrm{ug} / \mathrm{ml}$ & $1.78 \%$ & $2.01 \%$ \\
\hline
\end{tabular}
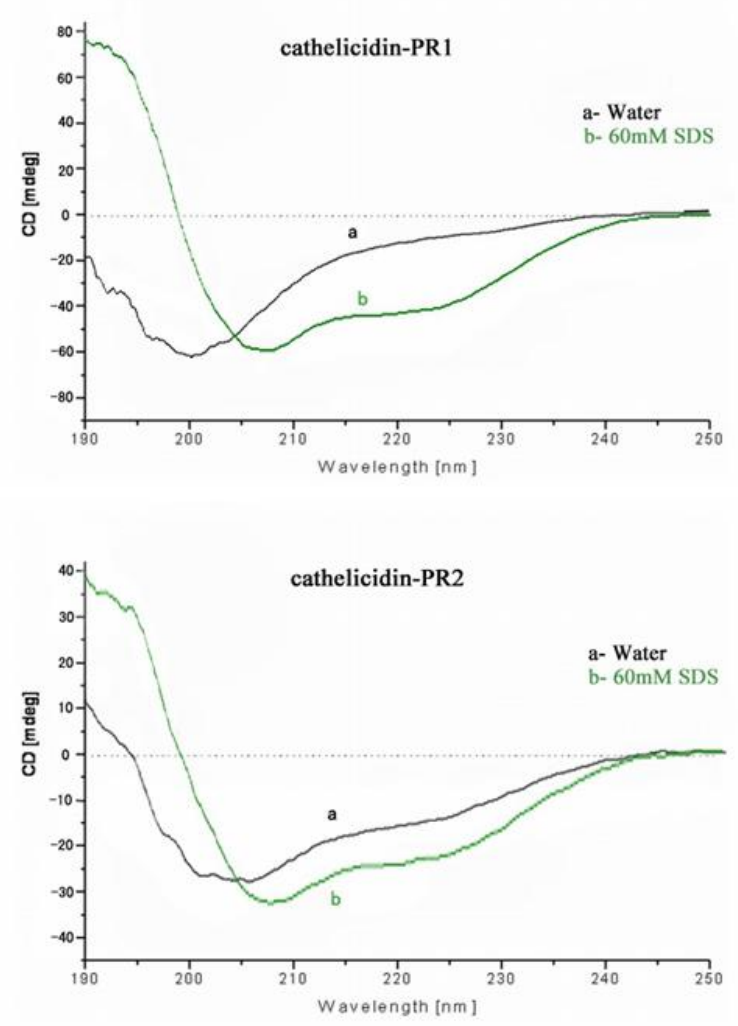

Fig. 4. Circular dichroism analysis of cathelicidin-PRs in ultrapure water (a) and SDS (60mM, b) solvent

Circular dichroism analysis is shown in Fig. 4. Both cathelicidin-PR1 and cathelicidin-PR2 had random coil configuration in sterile deionized water, while in $60 \mathrm{mM}$ sodium dodecyl sulfate (SDS) solvent, they had helix configuration, as predicted.

\section{CONCLUSIONS}

Recent studies have shown that cathelicidins act by interacting with the cell membrane of pathogenic microorganisms, leading to the formation of holes in the cell membrane, leakage of cell contents, and hence killing of pathogens [22]. Not every cathelicidin has antimicrobial activity [15,23]. This study showed that the charge of cathelicidin-PR1 was +7 , while the cathelicidin-PR2 net charge was 0 , and the cathelicidin-PR2 no antibacterial activity. It suggested that the antibacterial activity of cathelicidins was related to not only it's $\alpha$ - helix structure, but also its charge number. 
Cathelicidins have potential clinical and agricultural value. At present, Cathelicidin PR1 and cathelicidin PR2 genes were tandem ligated and successfully expressed in E. coli BL21 by prokaryotic expression [24].

Bacillus cereus can cause human food poisoning, causing symptoms such as nausea, vomiting and abdominal pain. Cathelicidin PR1 has higher antimicrobial activity than ampicillin on the kill $B$. cereus, and also cathelicidin-PR1 has broadspectrum antimicrobial activity. This indicates that Cathelicidin-PR1 is an important resource for the development of new anti-infection drugs, especially some strains that are resistant to traditional antibiotics. Cathelicidin-PR1 and cathelicidin-PR2 exhibited very low hemolytic activity against human erythrocytes and little hemagglutinating activity. The results suggested that the cathelicidin-PR1 might serve as a template for developing novel antibiotics.

\section{ETHICAL APPROVAL}

All animal experimental protocols were approved by the Animal Care and Use Ethics Committee of Guizhou Normal University.

\section{ACKNOWLEDGEMENT}

This study was supported by Deng's Doctor Research Fund of Guizhou Normal University. We are thankful for this support.

\section{COMPETING INTERESTS}

Authors have declared that no competing interests exist.

\section{REFERENCES}

1. Zasloff M. Antimicrobial peptides of multicellular organisms. Nature. 2002;415:389-395.

2. Zanetti M, Gennaro R, Romeo D. Cathelicidins: a novel protein family with a common proregion and a variable Cterminalantimicrobial domain. FEBS Letters. 1995;374:1-5.

3. Zaiou M, Gallo RL. Cathelicidins, essential gene-encoded mammalian antibiotics. J Mol Med. 2002;80: 549-561.

4. Uzzell T, Stolzenberg ED, Shinnar AE, Zasloff M. Hagfish intestinal antimicrobial peptides are ancient cathelicidins. Peptides. 2003;24:1655-1667.
5. Dürr UHN, Sudheendra US, Ramamoorthy A. LL-37, the only human member of the cathelicidin family of antimicrobial peptides. Biochim Biophys Acta. 2006;1758:1408-1425.

6. Wang Y, Hong J, Liu X, Yang H, Liu R, Wu J, Wang A, Lin D, Lai R. Snake Cathelicidin from Bungarus fasciatus is a Potent Peptide Antibiotics. PLoS ONE. 2008;3:e3217.

7. Zanetti M, Del SG, Storici P, Schneider C, Romeo D. The cDNA of the neutrophil antibiotic Bac5 predicts a pro-sequence homologous to a cysteine proteinase inhibitor that is common to other neutrophil antibiotic. J Biol Chem. 1993;268:522-526.

8. Hao X, Yang H, Wei L, Lai R. Amphibian cathelicindin fills the evolutionary gap of cathelicidin in vertebrate. Amino Acids. 2012;43:677-685.

9. Wei L, Yang JJ, He XQ, Mo GX, Hong J, Yan XW, Lin DH, Lai R. Structure and function of a potent lipopolysaccharidebinding antimicrobial and anti-infiammatory peptide. Journal of Medicinal Chemistry. 2013;56:3546-3556.

10. Kopitar M, Ritonja A, Popovic T, Gabrijelcic D, Krizaj I, Turk V. Primary structure of a new cysteine proteinase inhibitor from pig leukocytes, FEBS Lett. 1989;255:211-214.

11. Zanetti M, Gennaro $R$, Scocchi M, Skerlavaj B. Structure and biology of cathelicidins. The Biology and Pathology of Innate Immunity Mechanisms. 2000;479:203-218.

12. Turner J, Cho $\mathrm{Y}$, Dinh NN, Waring AJ, Lehrer RI. Activities of LL-37, a cathelinassociated antimicrobial peptide of human neutrophils. Antimicrob Agents Chemother. 1998;42:2206-2214.

13. Tack BF, Sawai MV, Kearney WR, Robertson $A D$, Sherman MA, Wang $W$, Hong T, Boo LM, Wu HY, Waring AJ, Lehrer RI. SMAP- 29 has two LPS - binding sites and a central hinge. Eur J Biochem. 2002;269:1181-1189.

14. Ling GY, Gao JX, Zhang SM, Xie ZP, Wei L, Yu HY, Wang YP. Cathelicidins from the Bullfrog Rana catesbeiana provides novel template for peptide antibiotic design. PLoS ONE. 2014;9(3): e93216.

15. Guang $\mathrm{H}$, Li Z, Wang $\mathrm{Y}$, Lai R, Yu H. Progress in cathelicidins antimicrobial peptides research, zoological research 33:523-526 Hancock REW, Scott MG. 2000. The role of antimicrobial peptides in animal defense. Proc. Natl. Acad. Sci. 
2012;97(16):8856-8861.

16. Hancock REW. Cationic peptides: Effectors in innate immunity and novel antimicrobials. The Lancet Infectious Diseases. 2001;:I:156-164.

17. Lai R, Liang J, Zhang Y. Antimicrobial peptides in amphibian skins and their application. Zoological Research. 2004;25:456-468

18. Lu Z, Zhai L, Wang H, Che Q, Wang D, Feng $F$, Zhao $Z$, Yu $H$. Novel families of antimicrobial peptides with multiple functions from skin of Xizang plateau frog, Nanorana parkeri, Biochimie. 2010;92:475481.

20. Fujii Y, Dohmae N, Takio K, Kawsar SMA, Matsumoto R, et al. A lectin from the mussel Mytilus galloprovincialis has a highly novel primary structure and induces glycan-mediated cytotoxicity of globotriaosylceramide expressing lymphoma cells. J Biol Chem. 2012;287:44772-44783.
21. Li J, Wu H, Hong J, Xu X, Yang $\mathrm{H}$, et al. Odorranalectin is a small peptide lectin with potential for drug delivery and targeting, PLoS ONE. 2008;3:e2381.

22. Wei L, Gao J, Zhang S, Wu S, Xie Z, Ling G, Kuang Y, Yang Y, Yu H, Wang Y. 2015. Identification and characterization of the first Cathelicidin from sea snakes with potent antimicrobal and anti-inflammatory activity, and special mechanism. Journal of Biological Chemistry. 2015;290:16331652.

23. Ma $Q Q$, Jiao $W J$, Wang $Z Y$, Wu $C X$, Shan AS, Wang YB, Cai J. Tissue specificity and species superiority of cathelicidin gene expression in Chinese Indigenous Min pigs. Livestock Science. 2013;161:36-40.

24. Deng $H Q$, Chen $C$, Xiao N, Zhou J. Prokaryotic expression of antimicrobial peptide CATH PR1-2 from the skin of Paa robertingeri in Escherichia coli. Asian Herpetological Research. 2017;8(4):275283.

(c) 2019 Luo et al.; This is an Open Access article distributed under the terms of the Creative Commons Attribution License (http://creativecommons.org/licenses/by/4.0), which permits unrestricted use, distribution, and reproduction in any medium, provided the original work is properly cited. 